\title{
Em que se sustenta a educação dos terraplanistas e criacionistas?
}

\section{What is the education of flat-earthers and creationists supported by?}

\author{
¿En qué se basa la educación de los terraplanistas y creacionistas?
}

\author{
MARILIA GOUVEA DE MIRANDA* \\ Universidade Federal de Goiás, Goiânia- GO, Brasil.
}

\begin{abstract}
RESUMO: $\mathrm{O}$ artigo discute as implicações do negacionismo científico para a educação escolar. Parte do pressuposto de que o neoconservadorismo, de que o negacionismo científico é uma expressão, decorre das contradições geradas pelo processo de neoliberalização. Quando o aparato produtivo acionado pela ciência e tecnologia produz, contraditoriamente, a negação da própria ciência, atualizando a depreciação da racionalidade e da autonomia intelectual, quais as consequências para a educação?
\end{abstract}

Palavras-chave: Neoliberalismo; Neoconservadorismo; Negacionismo científico; Educação escolar.

\begin{abstract}
The article discusses the implications of scientific negationism for school education. It starts from the assumption that neoconservatism, that scientific negationism is an expression, stems from the contradictions generated by the process of neoliberalization. What are the consequences for education when the productive apparatus triggered by science and technology produces, contradictorily, the negation of science itself, contemporizing the depreciation of rationality and intellectual autonomy?
\end{abstract}

Keywords: Neoliberalism. Neoconservatism. Scientific negationism. Schooling.

\footnotetext{
Mestra em Educação pela Universidade Federal de São Carlos e Doutora em História e Filosofia da Educação pela Pontifícia Universidade Católica de São Paulo. É Professora Titular aposentada da Universidade Federal de Goiás. E-mail:<mgmiranda8888@gmail.com>.
} 
RESUMEN: El artículo analiza las implicaciones del negacionismo científico para la educación escolar. Se parte del supuesto de que el neoconservadurismo, de que el negacionismo científico es una expresión, surge de las contradicciones generadas por el proceso de neoliberalización. Cuando el aparato productivo accionado por la ciencia y la tecnología produce, contradictoriamente, la negación de la ciencia misma, actualizando la depreciación de la racionalidad y la autonomía intelectual, ¿cuáles son las consecuencias para la educación?

Palabras llave: Neoliberalismo; Neoconservadurismo; Negacionismo científico; Educación escolar.

\section{Introdução}

$\mathrm{E}$ m um trabalho recente, em que tratei de algumas questões relativas ao neoliberalismo e ao neoconservadorismo, indaguei ao concluir: "se a terra é plana, em que bases se sustenta a educação?" (MIRANDA, 2020, p. 11). A pergunta sugeria que um mundo concebido aos moldes do terraplanismo é uma ameaça para a educação escolar quando compreendida como uma instituição de caráter público que, historicamente, busca se configurar como locus de formação e autonomia, a despeito de todas as adversidades que teve e tem de enfrentar em uma sociedade de classes.

Como é sabido, o estágio atual do capitalismo imperialista, que se distingue pela financeirização do capital e pelo neoliberalismo, tem resultado no aumento da concentração de riqueza, no aprofundamento brutal das desigualdades sociais e no incremento do conservadorismo conduzido por movimentos de setores da direita cada vez mais ruidosos e organizados. Suas manifestações obscurantistas, ainda que, em aparência, se manifestem irracionais e localizadas em alguns setores da sociedade, essencialmente fazem parte das estratégias de dominação conduzidas sob o neoliberalismo. O fortalecimento dos movimentos conservadores não se revela, assim, como um processo que vem se somar ao neoliberalismo, mas, ao contrário, lhe é inerente.

Do pressuposto de que o avanço do neoconservadorismo decorre das contradições geradas pelo processo de neoliberalização é que a questão acerca das bases da educação é retomada neste artigo. Afinal, o que caberá à educação quando o aparato produtivo acionado pela ciência e tecnologia produz, contraditoriamente, a negação da própria ciência, atualizando a depreciação da racionalidade e da autonomia intelectual? Afinal, o que resta à educação em tempos de guerra contra a ciência e a razão?

A descrença nos resultados consolidados da ciência, dentre tantas outras manifestações emblemáticas desse movimento neoconservador e obscurantista, vem sendo chamada de negacionismo (denialism) científico. Diethelm e Mckee (2009) (citados por 
ROCHEL DE CAMARGO; MEDINA COELI, 2020, p. 2), apoiando-se nos irmãos Hoofnagle, assim compreendem o negacionismo científico: "emprego de argumentos retóricos para dar a aparência de debate legítimo onde nenhum existe, uma abordagem que tem como objetivo último rejeitar uma proposição sobre a qual existe consenso científico". Segundo essas mesmas fontes, o negacionismo seria caracterizado por: "1) identificação de conspirações; 2) uso de falsos experts; 3) seletividade, focalizando em artigos isolados que contrariam o consenso científico ("cherry-picking"); 4) criação de expectativas impossíveis para a pesquisa; e 5) uso de deturpações ou falácias lógicas" (ROCHEL DE CAMARGO; MEDINA COELI, 2020, p.2).

Não se pode afirmar, contudo, que a negação da ciência seja um fenômeno exclusivamente contemporâneo. São conhecidas, por exemplo, as agruras dos primeiros filósofos e cientistas no advento do mundo moderno: muitos tiveram suas vidas ceifadas ou foram banidos e segregados até que fosse permitido separar a vida natural da vida espiritual, a matéria do espírito e até que pudessem combater as crenças e abrir caminho para o pensamento autônomo e metódico das modernas formas de pensamento. Nos desdobramentos que se seguiram, a ciência ainda vem enfrentando a oposição das forças conservadoras das religiões, dos movimentos ultrarreacionários e dos governos totalitários.

Na atualidade, é crescente o número de pessoas que afirma que a Terra é plana e acredita que a Nasa conspira, diligentemente, para nos fazer crer no contrário. São os negacionistas terraplanistas, um grupo cada vez mais numeroso no Brasil: $7 \%$ da população, segundo dados do Instituto Datafolha de julho de 2019 (GARCIA, 2019) ${ }^{1}$. De nada adiantaria recorrer às imagens de satélites para tentar demonstrar a esfericidade do planeta a esses 11 milhões de terraplanistas, porque essas fotos não seriam tidas como confiáveis para boa parte dos $26 \%$ dos brasileiros que, segundo o mesmo levantamento, sequer acreditam em que o homem tenha, algum dia, colocado os pés na lua (NOGUEIRA, 2019). Uma das características desse grupo é a sua baixa escolaridade: 10\% das pessoas que deixaram a escola após o ensino fundamental declararam acreditar que a terra é plana; dentre as que estudaram até o ensino médio, foram 6\%; e das que têm ensino superior, 3\% (GARCIA, 2019). Os terraplanistas são mais frequentes também na faixa etária acima de 60 anos (11\%). Do ponto de vista da ocupação, os assalariados sem registro, os estudantes e os aposentados são os que mais acreditam que a Terra é plana. Em resumo, tendem a se identificar com o terraplanismo os menos escolarizados, os que estão fora do mercado de trabalho formal e os mais velhos, ainda que estejam também distribuídos entre outros extratos desses segmentos. Os terraplanistas não apenas são um grupo numeroso em ascensão no Brasil, mas são cada vez mais estridentes e organizados em círculos nacionais e internacionais, favorecidos pelas mídias eletrônicas e redes sociais ${ }^{2}$, vários deles tendo conseguido galgar cargos políticos importantes e receber homenagens do poder público.

Um exemplo de teoria científica cercada por violentas oposições e calorosas controvérsias é a teoria da evolução darwinista. De seu nascedouro, quando já provocava 
reações entre aqueles que a apoiavam e aqueles que a refutavam com veemência, até o presente, o evolucionismo segue sendo combatido por grupos religiosos e conservadores, que defendem uma explicação criacionista para a origem da vida e sua diversidade, em geral fundamentada na literalidade da interpretação das escrituras bíblicas. Existem muitos negacionistas criacionistas no Brasil: uma pesquisa do Datafolha (2010) ${ }^{3}$, em que os entrevistados deveriam declarar sua concordância com algumas afirmações que lhes foram apresentadas, 59\% dos brasileiros disseram que acreditavam em uma evolução guiada por Deus, ao passo que $25 \%$ concordavam em que os seres humanos foram criados por Ele de uma só vez e em algum momento nos últimos dez mil anos. Apenas 8\% assentiram com a teoria de que não haveria qualquer intervenção divina no processo evolutivo. Há, portanto, uma alta tendência de adesão a uma explicação convergente entre ciência e religião, o que torna os brasileiros potencialmente muito receptivos ao discurso negacionista criacionista. O criacionismo tem, historicamente, provocado fortes embates no enfrentamento de questões ligadas à relação entre ciência e sociedade, desdobrando-se em ações que afetam vários setores da vida social, em particular, no que mais interessa discutir neste artigo, a educação.

Outros exemplos de negacionismo científico em vários campos de conhecimento poderiam ser citados, pois que tem sido cada vez mais frequente encontrar quem duvide da eficiência das vacinas, quem negue o genocídio dos judeus sob o nazifascismo, quem questione os dados indicativos do aquecimento global e dos incêndios nas florestas. $\mathrm{Ou}$, mais recentemente, quem recuse os benefícios do isolamento social da população e outras medidas de prevenção ao avanço da pandemia provocada pela Covid 19 (SANDONI, 2020). O negacionismo científico é, no entanto, seletivo com relação aos seus conteúdos e, em geral, não se destina à ciência como um todo. Isso permite, por exemplo, que a disseminação de "teses" do negacionismo científico possa ser operada por dispositivos tecnológicos sofisticados de base científica. Ou seja, o negacionismo da ciência utiliza como meio para tal a própria ciência ${ }^{4}$.

Ao desacreditar determinados setores ou aspectos da ciência, o negacionismo atinge toda a ciência em seus alicerces e, consequentemente, põe em causa um dos pilares do mundo moderno que é o suposto iluminista de que as ações humanas podem e devem ser conduzidas tendo por base a afirmação da razão e a perspectiva da emancipação humana. Os desdobramentos da modernidade conduziram, bem o sabemos, à instrumentalização da razão e ao aprisionamento dos seres humanos a uma ordem voltada para a exploração sob e a submissão aos interesses do capital. Nesse universo marcado por contradições, graças aos enfrentamentos daqueles que confrontam essa realidade, alguns fundamentos e valores emancipadores e civilizatórios teimam em persistir. É contra esses fundamentos e valores que, em grande medida, o negacionismo se orienta.

O objetivo deste artigo é discutir as implicações desse processo para a educação, ou seja, perguntar sobre o sentido e as possíveis consequências que esse processo 
acarretaria para a educação, particularmente a educação escolar. Para tanto, são discutidos, inicialmente, os desenvolvimentos do neoliberalismo e do neoconservadorismo na contemporaneidade e seus desdobramentos no fortalecimento do negacionismo científico para, em seguida, considerar suas implicações para a educação.

\section{Neoliberalismo e neoconservadorismo}

O neoliberalismo é, em essência, um atributo do capitalismo contemporâneo, uma combinação de globalização, neoliberalismo e financeirização do capital. Em linhas gerais, o neoliberalismo pode ser entendido como uma doutrina e uma política econômica fundamentadas na ideia de que o interesse do mercado deve prevalecer sobre todos os setores da vida humana, dos mais universais aos mais particulares. Ele envolve também uma concepção de Estado para a qual articula ideias e práticas que aprofundam a desigualdade econômica e levam à perda de valores e ideais políticos e sociais. Isto é, um Estado que, só na aparência, advoga para si a condição de Estado mínimo, poisé mínimo apenas quando reduz drasticamente ou extingue toda e qualquer restrição aos movimentos do grande capital, mas se mantém muito forte e atuante para regular e defender os interesses das elites econômicas. Como tudo isso implica, evidentemente, prejuízos e sofrimentos para a população, é necessário gerar um consentimento popular. Isso faz com que o neoliberalismo seja também uma ideologia, ou seja, o neoliberalismo forja uma maneira de interpretar o mundo, cria um terreno ideal para o desenvolvimento de uma espécie de senso comum. Assim compreendido, pode-se afirmar que o neoliberalismo é também constitutivo de um tipo de sociabilidade.

Em seu fundamento, o neoliberalismo é um projeto de recomposição do poder de uma classe (DUMÉNIL; LÉVY, 2014). Em outras palavras, é um "projeto político de restabelecimento das condições de acumulação do capital e de restauração do poder das elites econômicas" (HARVEY, 2008, p. 27). Para tanto, mantém "uma campanha inexorável contra tudo o que possa parecer 'social', de modo a priorizar tudo o que possa ser ou parecer 'econômico'" (IANNI, 2004, p. 332). Ao longo de mais de quatro décadas, seu propósito de estimular a acumulação tem acarretado um aprofundamento sem precedentes das desigualdades sociais e tem experimentado novas e ainda mais deletérias formas de exploração da força de trabalho:

O Estado neoliberal exerceu forte pressão sobre os- trabalhadores assalariados, restringiu seu poder de compra, promoveu a precarização das condições de trabalho, extinguiu ou limitou a seguridade social, reprimiu os sindicatos e muitas outras medidas que retiraram direitos e benefícios disponíveis e aprofundaram as formas de exploração da força de trabalho (MIRANDA, 2020, p. 6). 
Nada disso impediu, entretanto, que o neoliberalismo continuasse a ser tratado como bem-sucedido e como a "única alternativa". Muitos analistas viram na crise financeira de 2007-2008 nos Estados Unidos uma crise do próprio neoliberalismo. Outros tantos veem os mesmos sinais na gravíssima crise econômica gerada pela pandemia em 2020. Não se pode ignorar, contudo, que uma característica do neoliberalismo é a sua capacidade de se apropriar, a seu favor, das consequências das crises que ele próprio produz (DARDOT e LAVAL, 2005).

Com efeito, a neoliberalização resultou em uma grande variedade de "perdedores" econômicos e sociais cada vez mais subsumidos por um processo a que as possibilidades de contraposição vêm se mostrando distantes e aparentemente inalcançáveis.

A transformação das estruturas sociais, das instituiçães e das leis sob o neolibera-
lismo também tendeu a evacuar a esfera política de participação, representatividade
e legitimidade, tornando os "perdedores" cada vez mais incapazes de resistir a
esse sistema de acumulação e de conceber alternativas a ele. [.... Embora tenham
sido altamente vantajosos para a consolidação do neoliberalismo, esses resultados
promoveram o desengajamento em massa dos processos políticos e das práticas
constitucionais, criaram poderosas tendências à apatia e a à anomia solaparam a
hegemonia ideológica e a legitimidade política do neoliberalismo: com a erosão da
credibilidade dos partidos, líderes e organizações tradicionais, os caminhos ins-
titucionais para a dissidência tornaram-se mínimos (SAAD FILHO e MORAIS,
2018, p. 262).

Os "perdedores" tendem, assim, a desconfiar das instituições democráticas neoliberais e a atribuir aos "outros" a responsabilidade por suas grandes perdas ${ }^{5}$. Nesse compasso, dois pilares do capitalismo são corroídos: o compromisso iluminista com a ciência e a legitimidade das políticas democráticas (SAAD FILHO, 2020). As duas consequências estão fortemente vinculadas e ambas ajudam a compreender a escalada das forças conservadoras que se manifestam por meio de expedientes, como a negação da ciência, a ressurgência de teses criacionistas, as posturas irracionais, a recusa em admitir a diversidade e a intolerância face a posições divergentes.

Importante ressaltar que os movimentos conservadores, ainda que se distingam e, em determinados momentos, até mesmo se oponham aos fundamentos do liberalismo, não se constituem, na atualidade, como movimentos inicialmente apartados ou apenas admitidos ou agregados ao neoliberalismo, mas como movimentos que se ampliam e se fortalecem em decorrência das formas de resolução que as elites econômicas e setores diretamente a elas relacionados têm encontrado para enfrentar as contradições geradas pelo sistema de acumulação em curso. Dessa compreensão decorre que, a despeito de suas especificidades, o protagonismo dos "atores" que, efetivamente, ameaçam a educação escolar e a combatem sistematicamente no tempo presente - os neoliberais, os conservadores, religiosos ou não, e os gerencialistas, nos termos propostos por Apple (2004) referindo-se à educação americana nas últimas décadas do século passado nos Estados 
Unidos - resulta de uma mesma ordem de determinação vinculada ao sistema de acumulação. Nessa perspectiva, os movimentos neoconservadores se inscrevem nesse contexto neoliberal como uma estratégia que compõe o processo de restruturação do capital.

O neoliberalismo vai assumindo, nesse compasso, uma versão cada vez mais autoritária. São requeridas novas articulações e expedientes com vistas aos interesses imediatos do processo de acumulação, não importando o quanto estes venham a se afastar da base doutrinária do liberalismo clássico. O que inclui, ademais, romper com os princípios da democracia burguesa. Afinal, o mercado deve prevalecer sobre os interesses sociais, requerendo ações violentas do Estado sempre que necessárias, contando com o beneplácito dos setores mais conservadores da sociedade. Assim, o avanço da extrema direita - que chega ao poder em vários países, inclusive nos Estados Unidos, a economia capitalista mais importante do mundo, e em nosso país - não seria um processo externo ao neoliberalismo, mas um processo que lhe é inerente.

Essa questão se singulariza no contexto brasileiro desde o golpe de Estado de 2016, de natureza jurídica-midiática-parlamentar, quando teve início uma nova etapa neoliberal ${ }^{6}$, dessa feita com características autoritárias, resultado de uma composição entre as elites neoliberais (em especial, o setor financeiro), os militares e os conservadores religiosos, com o apoio decisivo dos meios de comunicação de massa, dos poderes judiciário e legislativo, de parte da classe média e de trabalhadores. Nesse processo, a classe dominante brasileira, mais uma vez, expressou seu ódio de classe e o fez articulando uma direita que foi, crescentemente, se revelando, nas ruas, nas redes sociais e na mídia convencional, como um setor marcado pelo ressentimento, pela fúria e pelo obscurantismo de fundamento religioso. A partir de então, vem se perpetuando a discussão sobre a natureza dessa articulação entre as forças neoliberais e as forças conservadoras que vêm operando nos dois governos subsequentes a 1916. As análises tendem a situar essas forças como distintas, mas convergentes na defesa de seus interesses. Essa compreensão - que, em parte, se justifica porque, aparentemente, seriam forças distintas - não se sustenta quando se tem em conta o protagonismo das elites neoliberais, que se impõe pela condução de medidas econômicas extremas em favor do processo de acumulação, beneficiando-se das permanentes contendas conservadoras e obscurantistas para encobrir "a passagem da boiada", como um deles qualificou, sem meias palavras, a selvageria no avanço de ações regressivas.

\section{A educação dos terraplanistas e criacionistas}

Um marco da agenda neoliberal autoritária instalada em 2016 é a aprovação da Emenda Constitucional n 95/2016 (EC 95), que estipula um limite de investimentos públicos nos próximos vinte anos. Dentre muitos outros impactos decorrentes da EC 95 para as políticas públicas no País, destaca-se, na área de educação, o compromisso com o 
cumprimento das metas contidas no Plano Nacional de Educação (2014-2024) (AMARAL, 2016). Nos governos que se seguiram a 2016, registram-se graves retrocessos na agenda educacional, orientados por "soluções" neoliberais, como as reformas do ensino médio (aprovada pela Lei nº 13.415/2017) e a aprovação da Base Nacional Comum Curricular, o encerramento ou o abandono de programas em curso, os expressivos cortes de orçamento, a intensificação de processos de privatização da esfera pública, além da adoção de uma pauta conservadora sem precedentes (DOURADO, 2019).

Entendendo, como descrito, que os movimentos neoconservadores se inscrevem no contexto neoliberal como uma estratégia orientada para os interesses do mercado, compreende-se que a condução das políticas educacionais posteriores ao golpe de Estado de 2016 não apenas faz convergir as pautas neoliberais e as pautas neoconservadoras, a despeito de suas aparentes contradições, mas subordina as últimas às primeiras. Implica, por exemplo, compreender que estão amalgamadas ações, como o corte orçamentário das universidades públicas, a medida provisória que impõe restrições à eleição de reitores e os reiterados ataques verbais de autoridades à universidade - de que ela seria um antro de decadência e depravação conduzido pela esquerda. Essas e tantas outras medidas estão concatenadas à produção das condições de privatização do público, direta ou indiretamente, e ao controle ideológico e doutrinário, objetivos que importam aos interesses de acumulação e de reprodução das classes dominantes brasileiras que, é preciso ressaltar, reproduzem-se e se perpetuam sem jamais terem deixado de sustentar - com o necessário aporte de violência - seu preconceito de classe, seu racismo, sua intolerância para com qualquer forma de pensamento político que não resulte na confirmação imediata de seus interesses.

Voltando à questão anunciada pelo título deste artigo, em que bases afinal se sustenta a educação no mundo dos terraplanistas e criacionistas neoliberais? Os terraplanistas e criacionistas são aqui tomados como um emblema dos movimentos conservadores que elegem a educação escolar como campo de batalha nessa quadra da história brasileira, nos quais se incluem, entre mais: todas as demais modalidades de anticientificismo; os ataques generalizados à educação escolar; a defesa da educação domiciliar; o movimento pela "Escola sem partido"; a desqualificação e o controle sobre a prática dos professores; o ataque à autonomia e à legitimidade das universidades públicas; a proliferação de escolas militares. Podem ser arrolados ainda os movimentos conservadores não diretamente direcionados para a escola, mas que incidem poderosamente sobre ela: as pautas e as práticas de conteúdo racista, sexista e contrárias ao movimento LGBTQ; o combate às religiões não majoritárias, em especial as de matriz africana.

Assim reunidos, esse conjunto de ações revela, entre mais, que a escola pública está na mira dos neoliberais neoconservadores. Essa amálgama entre forças neoliberais e neoconservadoras rejeita o processo de escolarização pública em todos os seus fundamentos: como locus de formação para autonomia, espaço de aquisição de conhecimentos 
socialmente produzidos, de acesso gratuito e inclusivo, de gestão democrática e comprometida com o papel social que, historicamente, lhe foi conferido em uma sociedade de classes a despeito de suas inerentes e avassaladoras contradições. A sanha espoliadora do neoliberalismo não esconde mais sua cobiça por esse imenso mercado que a escola pública ainda retém e avança sobre ela com suas intensivas estratégias (diretas e indiretas) de privatização, processo que, em decorrência das ações de ensino remoto desenvolvidas durante a pandemia, deverá ser incrementado exponencialmente (KLEIN, 2020). Haveria talvez um segmento não tão almejado pelo mercado, qual seja, os muito pobres, cuja educação deveria permanecer sobre os auspícios do Estado, mas devidamente subfinanciada, socialmente segregada, sob vigilância do ponto de vista doutrinário e, se necessário, sob o controle da força policial. Tudo o que se disse sobre o avanço dos neoliberais e neoconservadores converge para o aprofundamento desse quadro de desmonte da educação pública tradicional, por mais assustador que isso possa parecer.

Porque nada disso ocorre de um dia para o outro e, sobretudo, porque estamos falando de uma instituição mais do que centenária da sociedade liberal, estão em causa a destituição da legitimidade e a desautorização da autoridade profissional e ética da professora ou do professor, esse personagem que, com os seus estudantes, consolida uma parceria que é a base da experiência produzida pela escola tal qual a conhecemos. Já depauperados pelas perdas salariais, as professoras e os professores enfrentam toda sorte de espoliação das condições de trabalho e, agora, graças aos ataques dos neoconservadores, de todas as formas de deslegitimação de seu ofício, que vão de episódios de achincalhes a violências explícitas. Submetidos aos processos de conformação da sociabilidade neoliberal, tendo menos oportunidades de ações coletivas de reconhecimento de suas causas e lutas, condicionados pelo crescimento avassalador das igrejas evangélicas neopentecostais e pela mídia ideologicamente alinhada, professoras e professores também são passíveis de adotar posições neoconservadoras, contribuindo para a reprodução interna dos interesses e valores neoliberais.

Essa perda de legitimidade se traduz também no outro pilar do processo educativo: a mediação dos conhecimentos socialmente produzidos. A cada nova geração, deve ocorrer um processo pelo qual todos, sem exceção, devem dominar as linguagens, os fundamentos e os valores de sua cultura. Isso supõe a existência de pressupostos e paradigmas teóricos e epistemológicos racionais que, a despeito das distinções e mesmo contradições, dão suporte à experiência humana de sistematização dos saberes em distintas possibilidades, como a filosofia, a ciência, a arte e a tecnologia, e também de sistematização dos aspectos normativos e axiológicos da vida em sociedade. Essa racionalidade é também condição para que a escola possa cumprir suas finalidades educativas. Não há como sustentar o sentido da educação na ausência dessa condição, a despeito de toda divergência, e que deve ser enfrentada, sobre os limites e as contradições da racionalidade científica 
e suas implicações sociais sob o capitalismo. Uma educação submetida ao negacionismo da ciência é, por princípio, impossível.

Mais difícil ainda seria supor um processo de socialização mediado pela escola que não tivesse por fundamento o desenvolvimento da autonomia de ação e de pensamento de sujeitos capazes de reconhecer no outro a condição de sua própria existência em sociedade. Se a sociabilidade neoliberal tende a fomentar todas as formas de preconceitos e a eliminar todas as manifestações de alteridade que não a confirmem, ela é incompatível com qualquer prática educativa. Se a escola se prestasse ou mesmo que, eventualmente, já se preste a fomentar essa sociabilidade neoliberal, certamente será porque o referido desmonte da escolarização pública já está em curso. Nesse sentido, é importante compreender em que direção apontam os processos de socialização mediados pelas escolas militares, pela escolarização domiciliar e, ainda, pela desescolarização prenunciada pelas experiências de ensino remoto para o período posterior à pandemia.

Por todos esses aspectos, as bases que sustentam a educação estão sob ameaça no mundo dos terraplanistas e criacionistas. Esse processo vem ocorrendo em esfera planetária, já que decorre do estágio atual do capitalismo, mas suas particularidades no País, onde a universalização de uma educação pública de qualidade jamais se realizou, podem contribuir para que seus efeitos sejam particularmente destrutivos. Nossas elites, que nunca adotaram a educação pública como prioridade e têm se mostrado conservadoras em todos os aspectos, encontram-se, hoje, na condição de aprofundar esse processo, ainda mais pelo que lhes asseguram o ponto de vista do mercado, o controle ideológico e a manutenção de seu ódio de classe. Advém daí a compreensão de que, se é grande a ameaça à educação escolar pública, ainda maior será a luta a ser empreendida em sua defesa.

Recebido em: 17/10/2020 e Aprovado em: 05/12/2020

\section{Notas}

1 Foram entrevistadas 2.086 pessoas com 16 anos ou mais em 130 municípios brasileiros, em 4 e 5 de julho de 2019; a margem de erro máxima foi de dois pontos percentuais, para mais ou para menos, dentro do nível de confiança de 95\%. (GARCIA, 2019).

2 Estudos recentes destacam o protagonismo do YouTube na produção do terraplanismo e no incentivo ao desenvolvimento de seus argumentos de apoio. (PAOLILLO, 2018).

3 Pesquisa Datafolha (2018) realizada nos dias 25 e 26 de março de 2010, com 4.158 pessoas de 168 municípios. A margem de erro foi de dois pontos percentuais, para mais ou para menos.

4 Uma característica do nazifascismo foi a combinação de "crenças malucas sobre o mundo com um confiante domínio de alta tecnologia contemporânea" (HOBSBAWN, 1994, p. 122). O historiador acrescenta: "O fim do 
século XX, com suas seitas fundamentalistas brandindo as armas da televisão e da coleta de fundos programada em computador, nos familiarizou mais com esse fenômeno."

5 No Brasil contemporâneo, os "outros" são, entre muitos, os pobres, os negros, os povos originários, os imigrantes, as religiões minoritárias e a comunidade LGBTI.

6 "Menos do que uma doutrina política, filosófica e/ou moral, o neoliberalismo fica constrangido a se apresentar fundamentalmente como uma receita de política econômica (abertura, Estado mínimo, desregulamentação etc.), desprezando, nessa medida, alguns dos nobres valores universais que primariamente lhe deram origem." (PAULANI, 2005, p.124).

\section{Referências}

AMARAL, Nelson C. PEC 241: a "morte" do PNE (2014-2014) e o poder de diminuição dos recursos educacionais. Revista Brasileira de Política e Administração da Educação, Goiânia, v. 32, n.3, p. 653-673, set./ dez. 2016.

APPLE, Michael W. Educando à direita: mercados, padrões, Deus e desigualdade. São Paulo: Cortez; Instituto Paulo Freire, 2003.

BRASIL. Emenda Constitucional nº 95, de 15 de dezembro de 2016. Altera o Ato das Disposições Constitucionais Transitórias para instituir o Novo Regime Fiscal e dá outras providências. Diário Oficial da União, Brasília, 2016.

CAPONI, Sandra. Covid-19 no Brasil: entre o negacionismo e a razão neoliberal. Estudos Avançados, São Paulo, v. 34, n. 99, p. 209-224, ago. 2020.

DARDOT, Pierre.; LAVAL, Christian. A nova razão do mundo: ensaio sobre a sociedade neoliberal. São Paulo: Boitempo, 2016.

DATAFOLHA. 59\% acreditam na evolução entre as espécies, sob o comando de Deus. Folha de São Paulo, São Paulo, n. 29.584, 2 abr. 2010.

DIETHELM, Pascal.; MCKEE, Martin. Denialism: what is it and how should scientists respond? The European Journal of Public Health, Oxford, v. 19, n. 1, p. 2-4, 2009.

DOURADO, Luiz Fernandes. Estado, educação e democracia no Brasil: retrocessos e resistências. Educação E Sociedade, Campinas, v. 40, e0224639, 2019.

DUMÉNIL, Gerárd.; LÉVY Dominique. A crise do neoliberalismo. São Paulo: Boitempo, 2014.

GARCIA, Rafael. 7\% dos brasileiros afirmam que a terra é plana, mostra pesquisa. Folha de São Paulo, São Paulo, Ciência, 14/07/2019.

HARVEY, David. O neoliberalismo: história e implicações. São Paulo: Loyola, 2008.

HOBSBAWN, Eric. Era dos extremos: o breve século XX: 1914-1991. São Paulo, Cia das Letras, 1994.

IANNI, Octávio. Capitalismo, violência e terrorismo. Rio de Janeiro: Civilização Brasileira, 2004.

KLEIN, Naomi. Capitalismo e coronavírus: “O choque é o próprio vírus”. Disponível em: http://www. ihu.unisinos.br/78-noticias/597194-naomi-klein-capitalismo-e-coronavirus-o-choque-e-o-proprio-virus. Acesso em 05/04/2020.

MIRANDA, Marília G. de. O neoliberalismo como ofensiva neoconservadora à educação brasileira. Revista Inter Ação, Goiânia, v. 45, n. 1, p. 1-15, 2020. 
NOGUEIRA, Salvador. Um em cada quatro brasileiros diz que pouso lunar é mentira. Folha de São Paulo, São Paulo, 16/07/2019. Ciência. Disponível em: https://www1.folha.uol.com.br/ciencia/2019/07/um-emcada-quatro-brasileiros-diz-que-pouso-lunar-e-mentira.shtml

PAOLILLO, John. C. The Flat Earth phenomenon on YouTube. First Monday, Chicago, v. 23, n, 12, $3^{\text {th }}$ December 2018. Disponível em: https://firstmonday.org/ojs/index.php/fm/article/download/8251/7693

PAULANI, Leda M. Modernidade e discurso econômico. São Paulo: Boitempo, 2005.

ROCHEL DE CAMARGO Jr., Kenneth; MEDINA COELI, Claudia. A difícil tarefa de informar em meio a uma pandemia. Physis: Revista de Saúde Coletiva, Rio de Janeiro, v. 30, n. 2, e300203, p. 1-5, 2020. Disponível em: https://www.scielo.br/pdf/physis/v30n2/0103-7331-physis-30-02-e300203.pdf

SAAD FILHO, Alfredo. Trump, Johnson, and Bolsonaro in the Swamp. The Bullet, Canadá, Public Good, 20 de julho de 2020. Disponível em: https://socialistproject.ca/2020/07/trump-johnson-bolsonaro-theswamp/

SAAD FILHO, Alfredo; MORAIS, Lecio. Brasil: neoliberalismo versus democracia. São Paulo, Boitempo, 2018. 